\title{
Dinâmica populacional de Protium Pallidum Cuatrec. em uma Floresta de Terra-Firme explorada seletivamente no estado do Pará, Brasil
}

O objetivo deste estudo foi determinar a influência das direções e das distâncias do centro das clareiras sobre o comportamento do ingresso, mortalidade e crescimento diamétrico de indivíduos com DAP $>5 \mathrm{~cm}$ de uma população de Breu Branco (Protium pallidum Cuatrec.), e determinar a distribuição diamétrica dessa espécie durante três anos de monitoramento em uma floresta primária após exploração seletiva. Foram implantadas cinco parcelas de $10 \mathrm{~m} \times 10 \mathrm{~m}$ em cada faixa onde foram avaliadas as variáveis: Ingresso (I\%), Mortalidade (M\%) e o Incremento Corrente Anual (ICA) em diâmetro. Os dados foram analisados através da análise de variância de três fatores. A espécie teve um índice de ingresso inicial de 16.6\%, com mortalidade nula no 10 ano, apresentando os maiores valores de crescimento diamétrico nas direções Norte e Sul, mostrando tendência à estabilização e distribuição diamétrica normalmente encontradas em florestas naturais, com maior número de indivíduos nas menores classes de tamanho.

Palavras-chave: Dinâmica florestal; Clareiras; Ingresso; Mortalidade e crescimento diamétrico.

\section{Population dynamics of Protium Pallidum Cuatrec. in a selectively logged Terra-Firme Forest in the state of Pará, Brazil}

This study had as objective determines the influence of the directions and of the distances of the center of the gaps on the behavior of the entrance, mortality and diameter growth of individuals with DAP $>5 \mathrm{~cm}$ of a population of White Pitch (Protium pallidum Cuatrec.), and determining the diameter distribution of that species for three years of studies in a primary forest after selective exploration. For so much, five portions of $10 \mathrm{~m} \times 10 \mathrm{~m}$ were implanted in each strip, where they were appraised the variables: Entrance (I \%), Mortality (M \%) and the Annual Current Increment ( $\mathrm{ACl}$ ) in diameter. The data were analyzed through the analysis of variance of three factors (directions, distances and the period of three years). The species had an index of initial entrance of $16.6 \%$, with null mortality in the 1 st year, presenting the largest values of diameter growth in the directions North and South, showing tendency to the stabilization and diameter distribution usually found at natural forests, with larger number of individuals in the smallest size classes.

Keywords: Forest dynamics; Gaps; Entrance; Mortality and diameter growth.

Topic: Ciências Florestais

Reviewed anonymously in the process of blind peer.
Received: 06/03/2021

Approved: $22 / 03 / 2021$
Stone César Cavalcante da Costa (iD)

Universidade Federal Rural da Amazônia, Brasil

http://lattes.cnpq.br/9972957553976362

http://orcid.org/0000-0003-1894-8118

stonecosta@yahoo.com.br

Fernando Cristóvam da Silva Jardim (iD)

Universidade Federal Rural da Amazônia, Brasil

http://lattes.cnpq.br/9093965063812492

http://orcid.org/0000-0002-9855-759X

fernando.jardim@ufra.edu.br

Francimary da Silva Carneiro (it)

Universidade Federal Rural da Amazônia, Brasil

http://lattes.cnpq.br/86572355442333319

http://orcid.org/0000-0002-1693-8779

francimarycarneiro@gmail.com

\author{
Marcio Braga Amorim (DD \\ Universidade Federal Rural da Amazônia, Brasi \\ http://lattes.cnpq.br/8687384932049856 \\ http://orcid.org/0000-0001-7508-2766 \\ marciobamorim@gmail.com \\ Klewton Adriano Oliveira Pinheiro (iD \\ Instituto Federal do Pará, Brasil \\ http://lattes.cnpq.br/8139678842009696 \\ http://orcid.org/0000-0003-2696-4249 \\ klewton.pinheiro@gmail.com
}

Referencing this:

COSTA, S. C. C.; JARDIM, F. C. S.; CARNEIRO, F. S.; AMORIM, M. B.; PINHEIRO, K. A. O.. Dinâmica populacional de Protium Pallidum Cuatrec. em uma Floresta de Terra-Firme explorada seletivamente no estado do Pará, Brasil. Revista Ibero Americana de Ciências Ambientais, v.12, n.3, p.13-28, 2021. DOI:

http://doi.org/10.6008/CBPC2179-6858.2021.003.0002 


\section{INTRODUÇÃO}

A compreensão da dinâmica dos processos que ocorrem ao longo do tempo em florestas inequiâneas é um grande desafio. Entender as mudanças, determinar suas principais causas e avaliá-las qualiquantitativamente é para estabelecer relações e prever consequências futuras, proporcionando ao manejador florestal condições de realizar um bom manejo (NAPPO et al., 2005).

O conhecimento sobre a dinâmica de populações das florestas tropicais é limitado, principalmente no que se refere ao estabelecimento, crescimento e mortalidade das espécies arbóreas. A maioria das florestas tropicais caracteriza-se fundamentalmente pela alta diversidade de espécies, baixa dominância e diversos padrões de dispersão espacial (HOSOKAWA et al., 1998).

Trabalhos envolvendo dinâmica de espécies vegetais se mostram essenciais para o estudo dos processos ecológicos da comunidade. Para que se possa avaliar adequadamente a dinâmica populacional de espécies vegetais é necessário realizar uma avaliação detalhada não só dos padrões espaciais de mortalidade e recrutamento, como das taxas de crescimento. Além disso, sabe-se que os padrões de mortalidade, recrutamento e crescimento podem variar consideravelmente ao longo dos anos. Estas variações podem estar ligadas ao clima e aos ciclos biológicos inerentes às espécies (CRAWLEY, 1997).

A melhor forma de enfocar a dinâmica de uma floresta, segundo Finegan (1992), é avaliando o crescimento, mortalidade, recrutamento e ingresso das espécies componentes dessa floresta. $O$ estudo da dinâmica, conforme Vanclay (1994) indica o crescimento e as mudanças na composição e na estrutura de uma floresta. O crescimento individual das árvores geralmente é avaliado, entre outras variáveis, principalmente pelo incremento diamétrico ou em área basal.

Os processos dinâmicos de uma floresta demonstram padrões de crescimento e mudanças em sua composição e estrutura. Portanto, a predição confiável destes processos, torna-se imprescindível para a adoção de tratamentos silviculturais adequadas para o manejo florestal sustentável (MENDONÇA, 2003).

Os estudos de ingresso, mortalidade e crescimento, a partir da formação de clareiras, são essenciais para a obtenção de informações básicas à elaboração de técnicas de manejo florestal. Silva (1989) comenta que o grau de perturbação no dossel e a composição florística influenciam bastante na qualidade de ingresso de novos indivíduos. Portanto, parte-se do princípio de que a sucessão florestal é iniciada com os distúrbios que ocorrem no dossel, portanto, com a formação de clareiras.

O recrutamento, segundo Carvalho (1997), é a admissão de um indivíduo em uma determinada população ou comunidade; o ingresso, segundo Alder et al. (1992), Carvalho (1997) e Vanclay (1994), referese ao surgimento de plantas em uma população no intervalo entre duas medições em parcelas permanentes.

A mortalidade refere-se ao número de indivíduos que foram mensurados inicialmente e que morreram durante o período de observação. Em florestas tropicais, o padrão de mortalidade natural no tempo e no espaço está fortemente relacionado à máxima longevidade das árvores, distribuição em classes de tamanho, densidade relativa das espécies, tamanho e número de aberturas no dossel da floresta. Perdas de árvores influenciam as condições do microambiente e consequentemente, a taxa de crescimento de 
árvores vizinhas, pois a morte de uma árvore pode aumentar ou reduzir a probabilidade da morte de outras (SWAINE et al., 1987).

A dinâmica da floresta está relacionada à sucessão ecológica e ocorre de forma diferenciada em relação ao processo de formação de clareiras. As clareiras formam um mosaico de diferentes estágios de desenvolvimento, iniciando com a fase de clareira, seguindo para construção e depois de estágio maduro. A abertura de clareiras é o principal fator para que diversas espécies existam na floresta, sendo renovadas e sustentadas pela dinâmica de perda de indivíduos mais velhos, permitindo a existência de outros indivíduos (CARVALHO, 1997).

Existem vários conceitos para clareira e, neste estudo, utilizou-se o de Popma et al. (1988) de que clareira é uma descontinuidade na cobertura florestal, cuja área engloba toda sua zona de influência até onde houver espécies pioneiras regenerando.

As diferentes definições de clareiras naturais parecem produzir resultados diferentes em pesquisas desenvolvidas em florestas tropicais e não têm conseguido incorporar as características ambientais distintas que se observa nas clareiras, como luminosidade, umidade e temperatura. São necessários estudos que indiquem uma definição a ser utilizada de forma mais consensual, que represente mais fielmente as características ambientais associadas às clareiras (ARMELIN et al., 2001).

As florestas nativas, geralmente caracterizam-se por apresentar distribuição diamétrica decrescente, em forma de "J-invertido ou exponencial negativa", ou seja, com maior abundância de indivíduos nas classes menores. Quando se trata de espécies isoladamente, existem várias formas, que vão desde a distribuição contínua de outras espécies, como as tolerantes à sombra, até a distribuição descontínua de outras espécies (intolerantes e intermediárias) (MORY, 2000).

As espécies tolerantes à sombra se caracterizam pelo contínuo recrutamento, devido à grande disponibilidade de sementes com curto período de viabilidade no solo o que não permite o acúmulo no banco de sementes. Entretanto, espécies desse grupo apresentam alta mortalidade, principalmente dos indivíduos mais jovens, que têm menos chances competitivas em relação aos maiores, o que justifica sua distribuição exponencial decrescente (MORY et al., 2001).

Neste contexto, o objetivo deste estudo foi determinar a influência das direções e das distâncias do centro das clareiras sobre o comportamento do ingresso e mortalidade de indivíduos com DAP $\geq 5 \mathrm{~cm}$ de uma população de Protium pallidum Cuatrec., assim como avaliar o crescimento diamétrico e determinar a distribuição diamétrica dessa espécie durante três anos de monitoramento em uma floresta primária após exploração seletiva no Município de Moju, no estado do Pará.

\section{REVISÃO TEÓRICA}

\section{Descrição geral da espécie Protium pallidum Cuatrec.}

\section{Características botânicas de Protium pallidum Cuatrec.}

O gênero Protium burm. f. contém aproximadamente 145 espécies de árvores tropicais, porém com 
nove limitadas ao Neotrópico. Como todas as Burseraceae, este gênero é caracterizado por todos os exemplos de folhas compostas, alternadas e imparipinadas com 1-9 ou mais pares de folíolos opostos.

Protium pallidum se distingue entre todas as espécies do gênero por causa da presença habitual de sapopemas e raízes de suporte e por causa da brancura do lado inferior dos folíolos. Dendrologicamente, são árvores geralmente de grande porte (10 a 31 metros de altura), máximo DAP registrado de $55 \mathrm{~cm}$, apresentando tronco cilíndrico e sapopemas (Figura 4), casca externa lisa, marrom a cinza, casca interna alaranjada, brilhosa, estriada, quando ferida exsuda uma resina clara, pegajosa, que ao secar fica branca e pulverulenta; Folhas jugadas (aos pares); Inflorescência subterminal; Flores pentâmeras; Fruto de cor verde quando maduro, geralmente ovoide e levemente comprimido dorso-ventralmente.

O breu branco é uma árvore nativa da Floresta Amazônica. Sua resina macia, de odor natural agradável e fresco, tem vários usos na cultura local, principalmente como defumador e incenso em rituais religiosos. É usado, também, como combustível e como ingrediente para a calafetação de canoas. Ao encontrá-lo no tronco, vê-se o reflexo claro da resina recém-exsudada, semelhante a uma pedra bruta incrustada na madeira, que exala seu perfume fresco e envolvente quando tocado. Quando não é extraído, o breu branco vai "amadurecendo" e se solidificando até cair no chão.
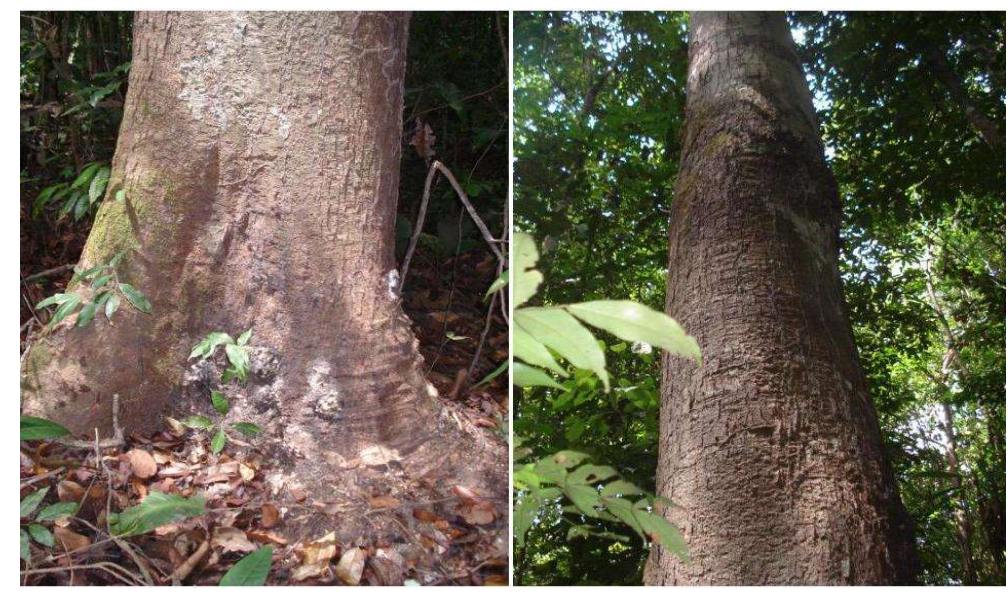

Figura 1: Base do tronco de Protium pallidum, mostrando sapopemas e vestígios da sua resina peculiar (A); Tronco de Protium pallidum (B).

\section{Distribuição geográfica de Protium pallidum Cuatrec.}

Embora representado por um número apreciável de espécimes nos herbários, $P$. pallidum é conhecido em poucos locais de coleção. Baseado nos dados de distribuição disponíveis, a espécie ocorre desde a Guiana Francesa central até o Amapá (porém interrompido pelas savanas do Amapá central) e norte do Pará até o oeste do Maranhão, com populações disjuntas na região ao redor de Manaus no Amazonas. A espécie é aparentemente comum na área ao redor de Belém. No Amapá central, é conhecido somente por ter o local do tipo, a Serra do Navio, onde em 1984 foram observados indivíduos estéreis. P. pallidum foi encontrado em duas localidades na Guiana Francesa, Mont La Fumée e Mont. St. Michel.

Até recentemente só havia uma coleção disjunta de $P$. pallidum na região de Manaus, mas foram achados alguns indivíduos da espécie nos inventários realizados durante os últimos anos pela World Wildlife Fundation-U.S. aproximadamente $80 \mathrm{~km}$ ao norte da cidade. Os espécimes dessa região emparelham com a 
coleção do tipo bem próxima ao Amapá.

Com poucas exceções, Protium pallidum é uma árvore frequentemente de sub-bosque, ou de dossel de floresta primária de terra firme em terreno ondulante. Existem duas coleções informadas em uma floresta inundada perto de Belém e uma em avançada floresta secundária ao leste de Belém próximo a Benevides. Outras espécies de Protium acontecem em países montanhosos, mas nenhuma mostra o forte desenvolvimento de sapopemas e raízes de suporte que caracterizam a espécie. Essa morfologia especializada pode explicar a grande habilidade competitiva da espécie (como indicado por sua alta densidade) como ocorre na Amazônia oriental. Ao longo de seu ciclo de vida, esta espécie floresce de agosto a novembro e frutifica de novembro a abril.

\section{MATERIAIS E MÉTODOS}

\section{Caracterização da área de estudo}

A área de estudo está localizada no Campo Experimental da Embrapa Amazônia Oriental, situado no km 30, à margem esquerda da Rodovia PA 150, no município de Moju, na microrregião 18 do Estado do Pará, distando 34 km da cidade de Moju (sede do município) e 115 km da cidade de Belém (Figura 2). Nessa área, inicialmente seriam desenvolvidas pesquisas da cultura de seringueira e dendezeiro, mas atualmente estão sendo desenvolvidas pesquisas de manejo florestal sustentável e agricultura familiar.

O Campo Experimental está situado entre as coordenadas geográficas de 2o 7' 57,03" e 20 18' 28,57" de latitude Sul e 48 47' 10,92" e 48 55' 0,35" de longitude a Oeste do meridiano de Greenwich, possuindo uma área de 1.059 hectares, na qual foram selecionados 200 ha, nos quais foi realizada uma exploração madeireira seletiva um ano antes do começo deste estudo.

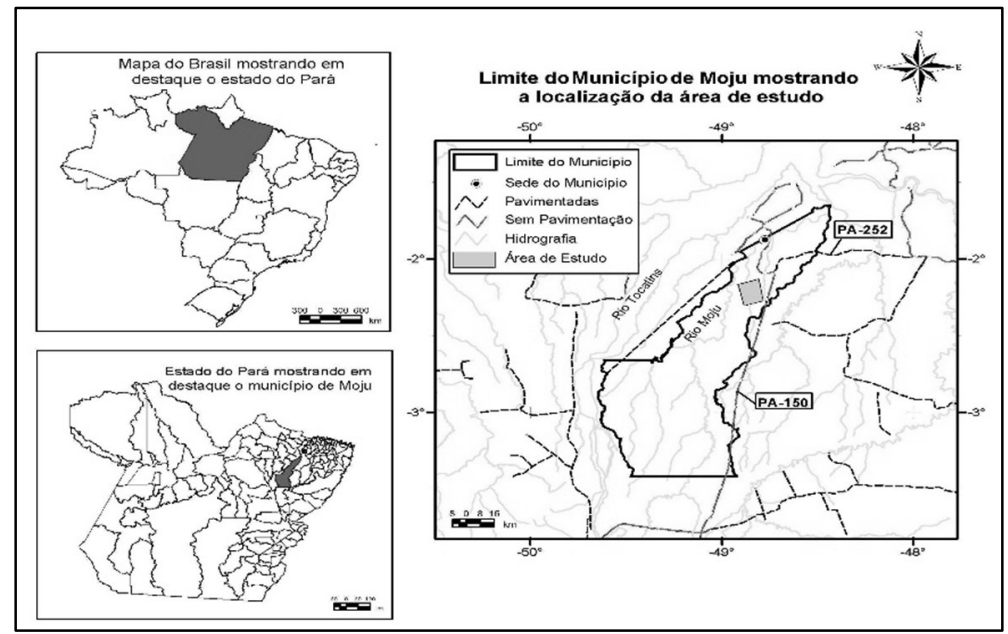

Figura 2: Localização da área de estudo, destacando o estado do Pará (A), o Município de Moju (B) e a Estação Experimental da Embrapa (C).

O clima da região é Ami (quente e úmido), segundo a classificação de Köppen, com temperatura média anual oscilando entre $25^{\circ} \mathrm{C}$ e $27^{\circ} \mathrm{C}$ e precipitação anual entre $2000 \mathrm{~mm}$ e $3000 \mathrm{~mm}$, com distribuição irregular e com ocorrência de dois períodos de chuva, o mais chuvoso abrangendo o período de janeiro a junho, concentrando cerca de $70 \%$ da precipitação anual. A insolação mensal varia entre 148,0 h e 275,8 h. 
O relevo é plano a suavemente ondulado, com pequenos desnivelamentos que variam de $0 \%$ a $3 \%$, e de $3 \%$ a $8 \%$ de declive, respectivamente, onde predominam solos bem drenados, classificados como Latossolos Amarelos e Argissolos Amarelos típicos e com suas fases pedregosas. Ao longo do Rio Ubá e Jacitara ocorre uma área deprimida estreita de várzea e uma pequena bacia que inundam no período chuvoso, onde são encontrados solos hidromórficos classificados como Gleissolos Háplicos e Plintossolos Argilúvicos.

A tipologia florestal da área experimental é Floresta Ombrófila Densa de terra firme. Possui árvores com o porte variando entre 25 a 35 m de altura com presença de algumas palmeiras no sub-bosque (LOPES et al., 2001; SILVA et al., 2001).

\section{Metodologia de coleta e análise de dados}

A coleta de dados foi realizada em uma área de 200 hectares de floresta tropical primária de terrafirme que sofreu exploração florestal seletiva em 1997, pela empresa Perachi Ltda., sob a orientação da Embrapa Amazônia Oriental. A área foi dividida em 2 blocos iguais de 100ha, onde foram inventariadas árvores de espécies comerciais com DAP $\geq 25 \mathrm{~cm}$ (bloco 2) e DAP $\geq 45 \mathrm{~cm}$ (bloco 1) (Costa et al., 1998).

Dessa exploração originaram-se diversas clareiras, dentre as quais nove foram utilizadas para a realização deste estudo (Figura 3), com áreas variando entre $231 \mathrm{~m}^{2}$ e $748 \mathrm{~m}^{2}$ (sendo que as áreas das clareiras foram calculadas considerando que as mesmas fossem retangulares). Com auxílio de equipamentos topográficos (trena, bússola), cada clareira teve seu centro determinado.

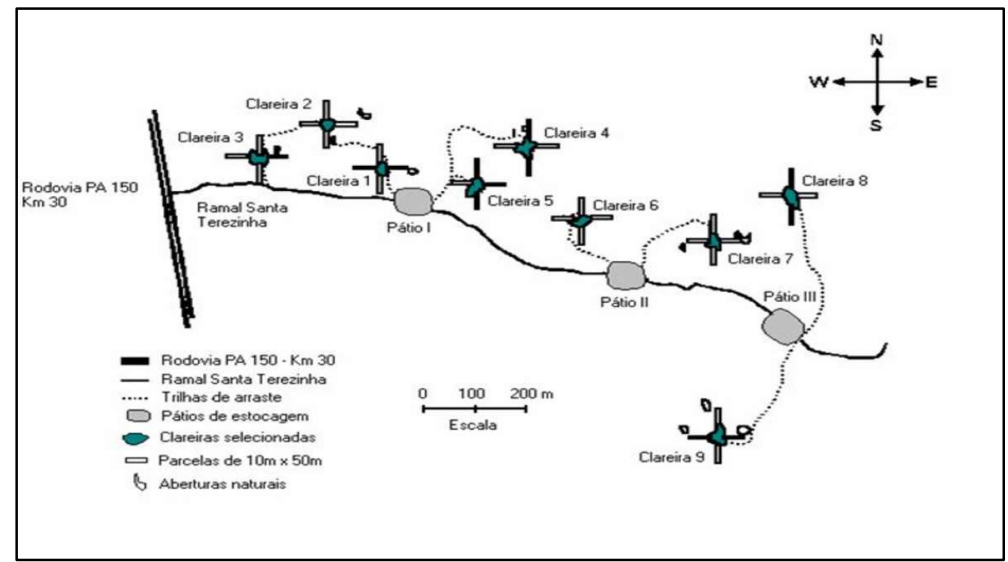

Figura 3: Desenho esquemático da disposição das nove clareiras selecionadas para estudo no Campo Experimental da Embrapa Amazônia Oriental em Moju - PA.

O presente estudo teve início em março de 1998, compondo a linha de pesquisa do projeto "Rendimento Sustentável em Floresta Tropical Manejada", de responsabilidade do Grupo de pesquisas MANEJO FCAP, que recebeu financiamento do CNPq (Conselho Nacional de Desenvolvimento Científico e Tecnológico) e SECTAM (Secretaria Executiva de Ciência, Tecnologia e Meio Ambiente)/FUNTEC (Fundo Estadual de Ciência e Tecnologia) e o apoio logístico da Embrapa Amazônia Oriental/UFRA e moradores da região. As atividades de coleta de dados foram realizadas trimestralmente, especificamente a partir do $20^{\circ}$ dia dos meses de março, junho, setembro e dezembro. Para este estudo, os dados analisados são 
correspondentes ao período de junho de 1998 a junho de 2001 (três anos).

Para o estudo da população de Protium pallidum com DAP $\geq 5 \mathrm{~cm}$ foram instaladas quatro faixas de $10 \mathrm{~m} \times 50 \mathrm{~m}$, divididas em parcelas de $10 \mathrm{~m} \times 10 \mathrm{~m}$, nas direções Norte, Sul, Leste e Oeste de cada clareira selecionada (Figura 4).

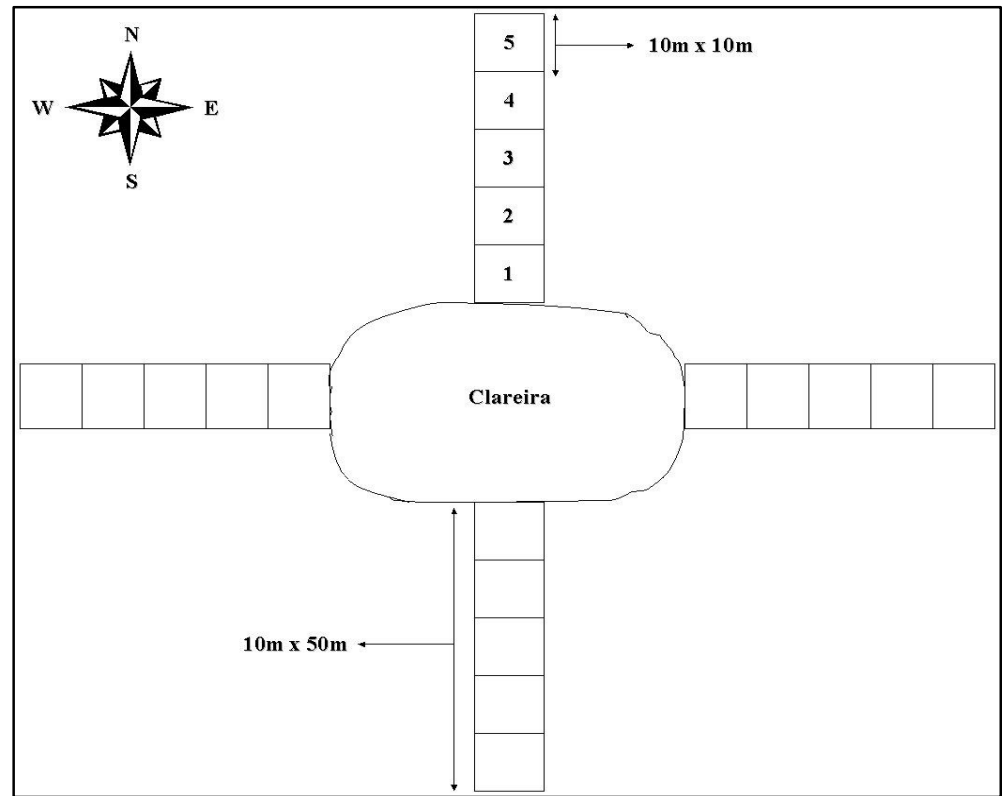

Figura 4: Desenho esquemático da distribuição das sub-parcelas de $10 \mathrm{~m} \times 10 \mathrm{~m}$ para o Nível Il de abordagem.

A dinâmica da população de Protium pallidum Cuatrec. com DAP $\geq 5 \mathrm{~cm}$ foi avaliada através do cálculo das Taxas de Ingresso (I\%) e Mortalidade (M\%) (variáveis dependentes) em relação às direções (Norte, Sul, Leste e Oeste) e em relação às distâncias do centro das clareiras para o interior da floresta (borda, 10, 20, 30 e 40m) (Figura 5).

Após isso, avaliou-se o crescimento diamétrico dos indivíduos da espécie através do Incremento Corrente Anual (ICA) em DAP e finalmente, determinou-se a distribuição diamétrica. Os resultados foram analisados estatisticamente no programa SYSTAT 10, através da Análise de Variância de três fatores (direções, distâncias e o período) sobre as variáveis dependentes (ingresso, mortalidade e ICA).

\section{RESULTADOS E DISCUSSÃO}

\section{Ingresso e mortalidade}

Os resultados da análise de variância de três fatores referentes aos dados de ingresso e mortalidade estão expressos nas Tabelas 1 e 2.

Tabela 1: Análise de Variância dos dados referentes às Taxas de Ingresso de Protium pallidum para o Nível II de abordagem (para $r^{2}=0,105$ ).

\begin{tabular}{lllll}
\hline Fonte de variação & GL & F & P & Significância \\
\hline Distância & 4 & 1,420 & 0,226 & NS* \\
Cardeal & 3 & 2,005 & 0,112 & NS \\
Ano & 2 & 0,501 & 0,606 & NS \\
Dist*Card & 12 & 0,752 & 0,700 & NS \\
Dist*Ano & 8 & 0,919 & 0,500 & NS \\
Card*Ano & 6 & 0,501 & 0,807 & NS \\
Dist*Card*Ano & 24 & 0,919 & 0,576 & NS
\end{tabular}


0,135

NS

Tabela 2: Análise de Variância dos dados referentes à Taxa de Mortalidade de Protium pallidum para o Nível II de abordagem (para $r^{2}=0,111$ ).

\begin{tabular}{lllll}
\hline Fonte de variação & GL & F & P & Significância \\
\hline Distância & 4 & 1,000 & 0,407 & NS* \\
Cardeal & 3 & 1,000 & 0,393 & NS \\
Ano & 2 & 1,000 & 0,369 & NS \\
Dist*Card & 12 & 1,000 & 0,448 & NS \\
Dist*Ano & 8 & 1,000 & 0,435 & NS \\
Card*Ano & 6 & 1,000 & 0,425 & NS \\
Dist*Card*Ano & 24 & 1,000 & 0,465 & NS \\
Tam. da Clar. & 1 & 0,951 & 0,330 & NS \\
Erro & 479 & & \\
\hline
\end{tabular}

I (\%) de Protium pallidum Cuatrec. com DAP $\geq 5 \mathrm{~cm}$ nas direções Norte, Sul, Leste e Oeste do centro das clareiras.

Não houve diferenças significativas nos valores de ingresso encontradas em função das direções $\left(F_{[2,005]}, P_{[0,112]}\right.$, Tabela 1$)$, embora se tenha encontrado valores mais altos para as direções Sul e Oeste (Figura $6)$.

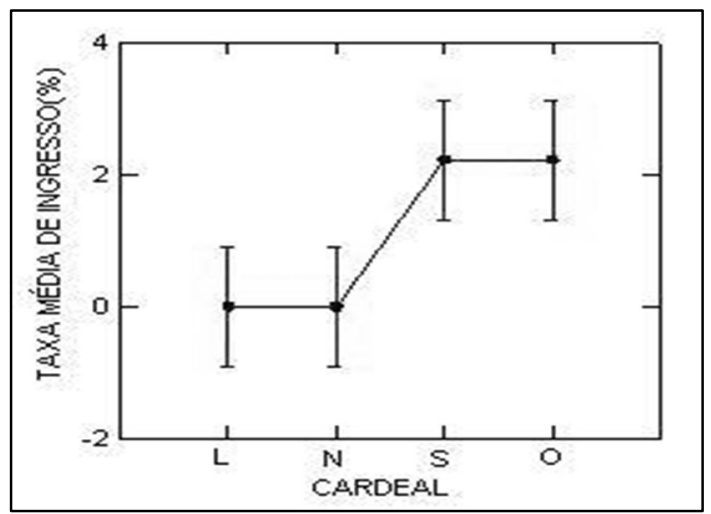

Figura 5: Médias de Taxa de Ingresso de Protium pallidum com DAP $\geq 5 \mathrm{~cm}$ em função das direções do centro das clareiras.

\section{I (\%) de Protium pallidum Cuatrec. com DAP $\geq 5 \mathrm{~cm}$ nas distâncias do centro das clareiras.}

Nos valores de ingresso em função das direções também não houve diferenças significativas $\left(F_{[1,420]}\right.$, $\mathrm{P}_{[0,226]}$, Tabela 1), contudo pode-se observar valores mais altos nas sub-parcelas a $30 \mathrm{~m}$ e nas bordas das clareiras (Figura 6).

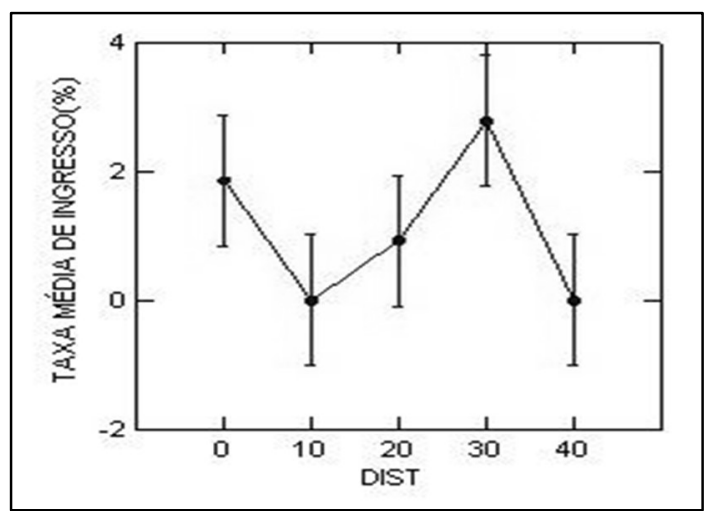

Figura 6: Médias seguida de desvio padrão de Taxa de Ingresso de Protium pallidum com DAP $\geq 5 \mathrm{~cm}$ em função das 
distâncias do centro das clareiras.

Comportamento de I (\%) de Protium pallidum Cuatrec. com DAP $\geq 5 \mathrm{~cm}$ nos três anos de monitoramento.

Não houve diferenças significativas nos valores de ingresso em função dos três anos de monitoramento ( $F_{[0,501]}, P_{[0,606]}$, Tabela 1) (Figura 7), no entanto observa-se que ao longo do estudo a taxa de ingresso diminuiu, mostrando tendência à estabilização.

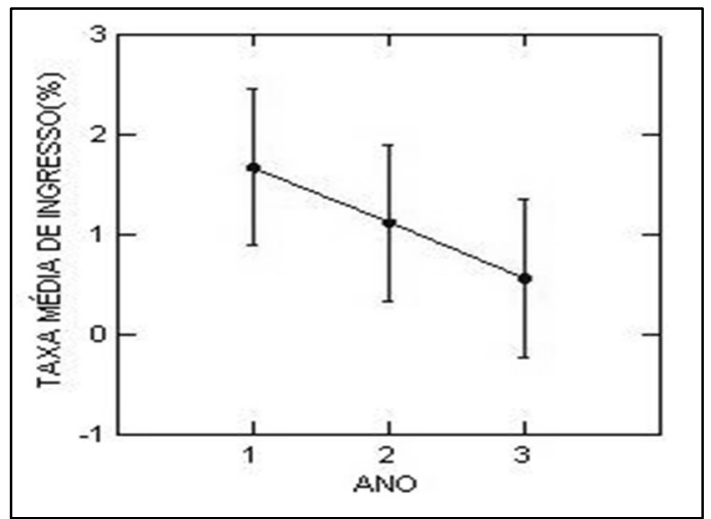

Figura 7: Médias de Taxa de Ingresso de Protium pallidum com DAP $\geq 5 \mathrm{~cm}$ em função do período de estudos.

M (\%) de Protium pallidum Cuatrec. com DAP $\geq 5 \mathrm{~cm}$ nas direções Norte, Sul, Leste e Oeste do centro das clareiras.

Não houve diferenças significativas nos valores de mortalidade encontradas em função das direções $\left(F_{[1,000]}, P_{[0,393]}\right.$, Tabela 2$)$, embora se tenha encontrado valores mais altos para as direções Sul e Oeste (Figura 8).

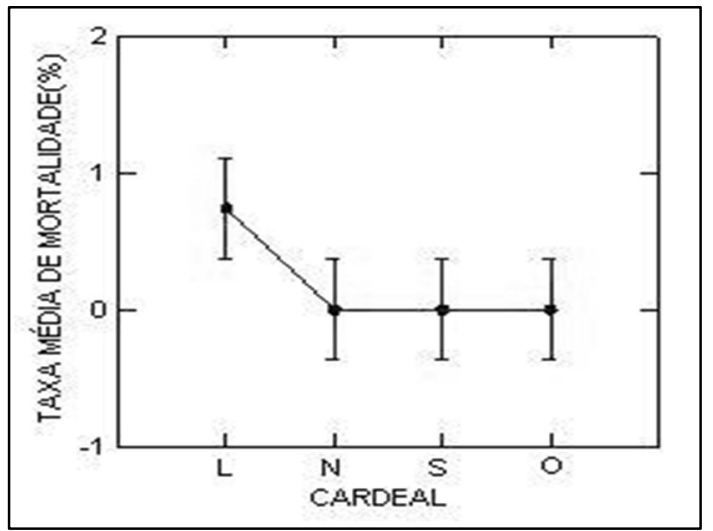

Figura 8: Médias de Taxa de Mortalidade de Protium pallidum com DAP $\geq 5 \mathrm{~cm}$ em função das direções do centro das clareiras.

M (\%) de Protium pallidum Cuatrec. com DAP $\geq 5 \mathrm{~cm}$ nas distâncias do centro das clareiras.

Não houve diferenças significativas nos valores de mortalidade encontradas em função das distâncias das clareiras $\left(F_{[1,000]}, P_{[0,407]}\right.$, Tabela 2) (Figura 9), embora se observou diferença para os valores nas subparcelas da borda das clareiras. 


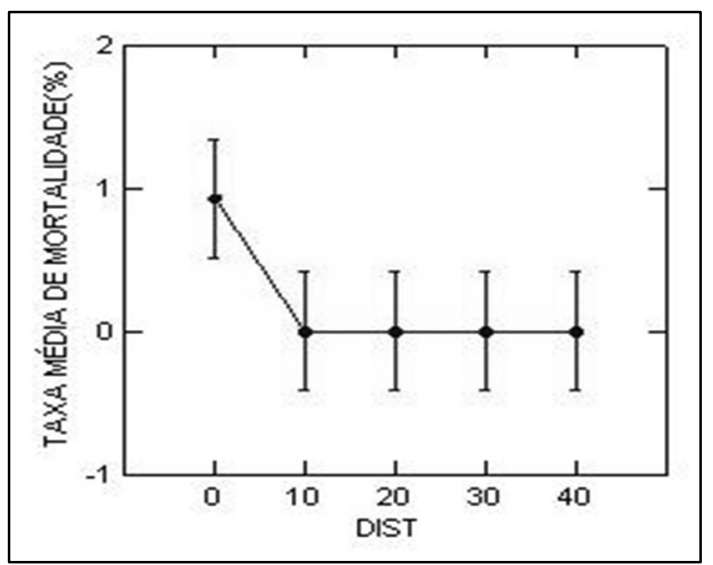

Figura 9: Médias de Taxa de Mortalidade de Protium pallidum com DAP $\geq 5 \mathrm{~cm}$ em função das distâncias do centro das clareiras.

\section{Comportamento da $\mathrm{M}(\%)$ de Protium pallidum Cuatrec. com DAP $\geq 5 \mathrm{~cm}$ nos três anos de monitoramento.}

Os valores de mortalidade em função dos três anos não mostraram diferenças significativas $\left(\mathrm{F}_{[1,000]}\right.$, $P_{[0,369]}$, Tabela 2) (Figura 10), no entanto observa-se que após registrar valores zero nos anos 1 e 2, a taxa de mortalidade subiu ao final do 30 ano.

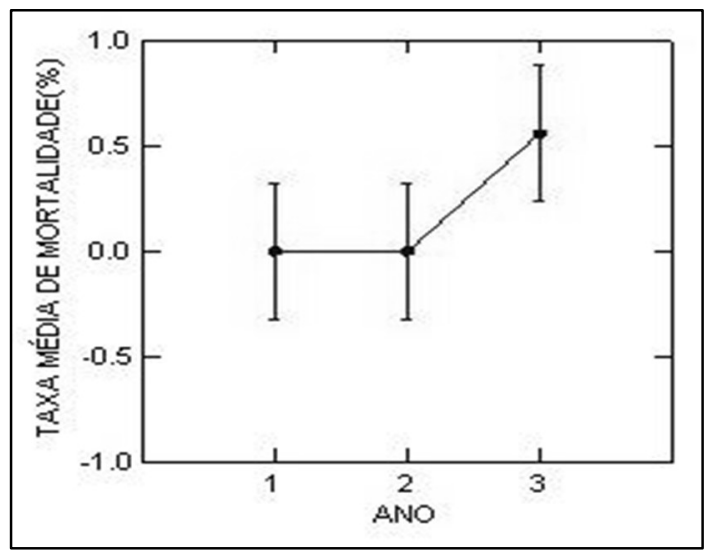

Figura 10: Médias de Taxa de Mortalidade de Protium pallidum com DAP $\geq 5 \mathrm{~cm}$ em função do período de estudos.

A abundância da população de Protium pallidum Cuatrec. Com $D A P \geq 5 \mathrm{~cm}$ não variou muito do início do estudo (junho de 1998) até o final (junho de 2001). O estudo registrou um número inicial total de 18 indivíduos, e um registro final de 23 indivíduos, ou seja, a população com DAP $\geq 5 \mathrm{~cm}$ teve um crescimento de indivíduos de $27,7 \%$ ou 5 indivíduos no decorrer de três anos de estudos.

Esse resultado de 23 indivíduos, relacionado ao tamanho total das parcelas amostrais que é de 1,8 ha, representa uma média de 12 indivíduos por hectare, o que é pequeno se comparado ao encontrado por Vasconcelos (2004), que registrou 177 indivíduos por hectare para a espécie $R$. guianensis Aublet, resultado este que posicionou a espécie em primeiro lugar em número de indivíduos no local de estudo.

Houve um decréscimo de 7,2\% entre os ingressos do 1 을 até o 30 ano. A mortalidade se manifestou apenas no 3 o ano, ainda assim baixa. Isso sugere que os indivíduos da espécie em fase mais adulta se mostram bastante resistente as condições de estudo, se comparados a população com DAP $<5 \mathrm{~cm}$. Apesar de uma ligeira tendência à estabilização, acredita-se que um monitoramento mais prolongado da área possa indicar melhor essa tendência, ou seja, o equilíbrio de ingresso e mortalidade. 
Lieberman et al. (1987), analisando florestas primárias na Costa Rica, relataram taxas de mortalidade de $1,9 \%$ ao ano. Manokaran et al. (1987) obtiveram mortalidade de 2,0\% ao ano em florestas primárias na Malásia, enquanto que Swaine et al. (1987) obtiveram 1,32\% em floresta tropical úmida na África.

Em floresta primária alterada no Pará, Silva (1989) obteve taxa de mortalidade de 4,7\% ao ano, enquanto que Carvalho (1997) obteve taxas de 4,3\% na mesma floresta.

Schorn (2005) reportou em seu trabalho sobre dinâmica de uma floresta ombrófila em BlumenauSC, durante três anos (2001 a 2003), que a porcentagem de mortalidade, considerada sobre a densidade existente em 2001, foi de 1,34\% ao ano, para todas as espécies no estágio inicial. Essa taxa de mortalidade está de acordo com os valores citados por Swaine et al. (1987), que obtiveram taxas de mortalidade entre 1 e $2 \%$ para florestas tropicais em diferentes continentes.

Vasconcelos (2004) registrou valores semelhantes para Rinorea guianensis, para as mesmas condições de estudo. No primeiro ano de seu estudo, a autora registrou um ingresso de $11,52 \%$ e uma mortalidade nula, indicando que a oferta de luminosidade logo após a formação da clareira, favoreceu o desempenho da espécie. No mesmo estudo, para o 2 ㅇ e 3 o anos, a autora encontrou valores de ingresso aproximados e a mortalidade foi crescente ao longo do tempo.

Além da ação do grau de perturbação sobre o comportamento da mortalidade, alguns autores como Manokaran et al. (1987), Swaine et al. (1987) e Lieberman et al. (1987) mencionam que o tempo transcorrido, desde a perturbação, também tem efeito notável sobre a mesma. Esses autores relataram ainda que florestas não alteradas mostram taxas de mortalidade constantes nas classes de DAP, e, dessa forma, nenhuma correlação com o tamanho da árvore é esperada. Em florestas exploradas, porém, Silva (1989) e Gomide (2003) observaram que a mortalidade tende a ser maior nas menores classes de tamanho e que, após algum tempo, quando a maioria das espécies pioneiras for substituída por tolerantes à sombra, a mortalidade tende a estabilizar e também se torna quase constante nas classes diamétricas.

\section{Crescimento diamétrico de Protium Pallidum Cuatrec.}

Os resultados da análise de variância de três fatores referentes aos dados de Incremento Corrente Anual (ICA) (em centímetros) de Protium pallidum estão expressos na Tabela 3.

Tabela 3: Análise de Variância dos dados referentes ao ICA de Protium pallidum (para $\mathrm{r}^{2}=0,106$ ).

\begin{tabular}{lllll}
\hline Fonte de variação & $\mathbf{G L}$ & $\mathbf{F}$ & $\mathbf{P}$ & Significância \\
\hline Distância & 4 & 3,421 & 0,009 & S $^{* *}$ \\
Cardeal & 3 & 3,670 & 0,012 & S** $^{*}$ \\
Ano & 2 & 0,410 & 0,664 & NS* \\
Dist*Card & 12 & 1,105 & 0,354 & NS \\
Dist*Ano & 8 & 0,526 & 0,837 & NS \\
Card*Ano & 6 & 0,370 & 0,898 & NS \\
Dist*Card*Ano & 24 & 0,474 & 0,985 & NS \\
Tam. da Clar. & 1 & 0,054 & 0,817 & NS \\
Erro & 479 & & &
\end{tabular}

* - Não significante;

** - Significante. 
Crescimento diamétrico de Protium pallidum Cuatrec. nas direções Norte, Sul, Leste e Oeste do centro das clareiras.

Houve diferenças significativas dos valores de ICA em relação às direções do centro das clareiras $\left(F_{[3,670]}, P_{[0,012]}\right.$, Tabela 3) (Figura 11). É possível observar na figura uma pequena vantagem das direções Sul e Norte em relação às outras direções.

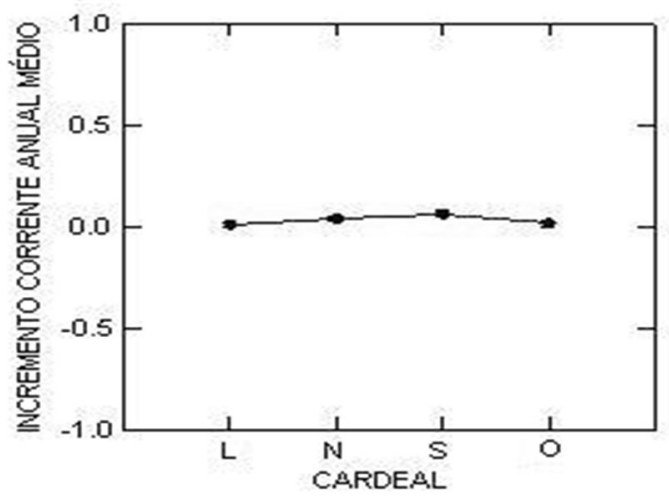

Figura 11: Médias de ICA (em $\mathrm{cm}$ ) de Protium pallidum com DAP $\geq 5 \mathrm{~cm}$ em função das direções do centro das clareiras.

\section{Crescimento diamétrico de Protium pallidum Cuatrec. nas distâncias do centro das clareiras.}

Nos valores de ICA em relação às distâncias do centro das clareiras também houve diferenças significativas $\left(F_{[3,421]}, P_{[0,009]}\right.$, Tabela 3) (Figura 13). Observa-se um pequeno decréscimo da sub-parcela da borda para a localizada a $10 \mathrm{~m}$ e a partir desta, um crescente aumento à medida que se adentra ao subbosque.

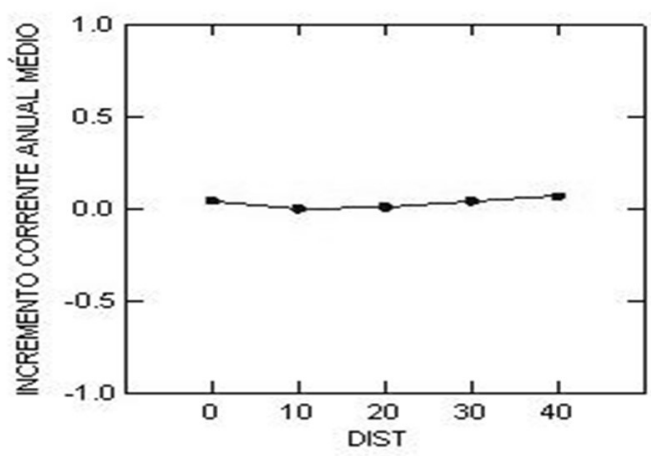

Figura 12: Médias de ICA $(\mathrm{em} \mathrm{cm})$ de Protium pallidum com DAP $\geq 5 \mathrm{~cm}$ em função das distâncias do centro das clareiras.

Crescimento diamétrico de Protium pallidum Cuatrec. com DAP $\geq 5 \mathrm{~cm}$ nos três anos de monitoramento.

Não houve diferenças significativas nos valores de ICA em função dos três anos $\left(\mathrm{F}_{[0,410]}, \mathrm{P}_{[0,664]}\right.$, Tabela 3) (Figura 13). Há uma pequena queda entre o 1ㅇ e 2ㅇ anos e pequeno aumento entre o 2을 30 anos.

Os maiores valores de crescimento diamétrico acumulado (3 anos) para Protium pallidum Cuatrec. foram registrados na direção Sul $(0,93 \mathrm{~cm})$, apresentando também o maior valor no 1 음 ano $(0,43 \mathrm{~cm})$ e no 3 은 ano $(0,31 \mathrm{~cm})$. O menor valor acumulado foi para a direção Leste $(0,13 \mathrm{~cm})$, que também apresentou os menores valores por ano $(0,03 \mathrm{~cm})$, no segundo e terceiro anos.

O maior valor de ICA para a população de Protium pallidum com DAP $\geq 5 \mathrm{~cm}$ foi de $0,78 \mathrm{~cm}$ para 0 
primeiro ano, havendo no segundo ano uma redução e no terceiro ano um aumento.

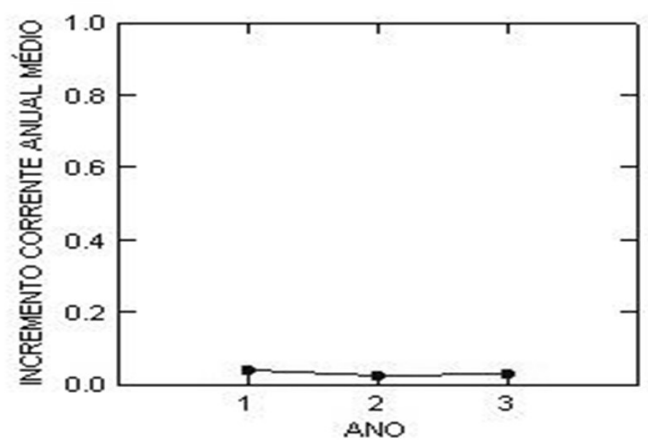

Figura 13: Médias de ICA (em $\mathrm{cm}$ ) de Protium pallidum com DAP $\geq 5 \mathrm{~cm}$ em função do período de estudos.

Novamente no eixo Norte-Sul (menor radiação solar), a espécie apresentou-se mais eficiente em termos de crescimento. Vasconcelos (2004) e Nemer (2003) encontraram resultados diferentes, pois seus resultados não apresentaram influência das direções. Segundo Malheiros (2001), a posição solar no infinito relativo condiciona a incidência de sua radiação num relativo paralelismo sobre as plantas distribuídas ao longo do eixo Norte-Sul. Com isso, a massa vegetal atravessada pela radiação é mais densa que aquela ao longo do eixo Leste-Oeste que atravessa a clareira. Assim sendo, o eixo Leste-Oeste oferece maior quantidade e qualidade de radiação fotossinteticamente ativa para as plantas.

Sugere-se então que no eixo norte-sul, onde a abundância é maior, possa existir um adensamento ou até um agrupamento de indivíduos da espécie, por algum motivo desconhecido, podendo ser por alguma condição especial do solo, ou até uma condição microclimática qualquer, porém não identificada, mas que favoreceu de algum modo o crescimento desses indivíduos.

Esses resultados são semelhantes aos encontrados por Vasconcelos (2004), que também observou uma pequena redução no ICA no segundo ano e acréscimo no terceiro, nas mesmas condições de estudo. Nemer (2003) observou apenas redução ao longo do estudo com Eschweilera odora, e considerou que seus resultados podem ter ocorrido em consequência da competição por água, luz e nutrientes com outras espécies, no ambiente densamente povoado em torno das clareiras.

Melo (2002), estudando duas comunidades arbóreas em Marituba e Bragança (ambas no Estado do Pará), encontrou uma média anual de incremento de 0,25 cm/ano entre 1997-2002 para a comunidade estudada em Marituba, considerando todas as árvores. Para Bragança, o incremento médio anual, entre os anos de 1999 e 2002, para todas as árvores foi de 0,25cm/ano. Em ambas as áreas, as menores taxas de crescimento médio anual foram apresentadas pelas árvores quebradas ou decapitadas. Esses danos severos restringem o crescimento diamétrico das árvores pela redução da superfície fotossintética.

Essa característica é mais comum em espécies (não-pioneiras) pertencentes a estádios mais avançados do processo de sucessão (PUTZ et al., 1989). Em Marituba, Melo (2002) reportou que $75 \%$ das espécies rebrotantes foram classificadas como tolerantes, entre as quais destacaram-se Virola melinonii, Didymopanax morototoni, Sclerolobium paraense, Ambelania acida, Eschweilera coriacea e Licania densiflora. Em Bragança, 53\% das rebrotantes eram espécies tolerantes e 37\% pioneiras, as demais não tiveram classificação definida. Nessa área destacaram-se, Terminalia amazônica, Croton matourensis, 
Saccoglottis amazônica, Eschweilera parvifolia, Eschweilera idatimon, Inga Alba, Tapirira guianensis e Inga rubiginosa com as maiores taxas de crescimento.

\section{Distribuição diamétrica}

A distribuição diamétrica da população total de Protium pallidum Cuatrec. apresentou maior número de indivíduos nas menores classes de diâmetro. Na 1a medição foram registrados 113 indivíduos na classe de diâmetro entre $5 \mathrm{~cm}$ e $10 \mathrm{~cm}$. A partir da 5 a medição (equivalente ao final do 10 ano), esse número de indivíduos aumentou e decresceu nos anos posteriores, sendo que o maior valor de DAP registrado foi de $20 \mathrm{~cm}$ (Figura 14). Assim como no estudo realizado por Vasconcelos (2004), sobre Rinorea guianensis para a mesma área, a espécie também apresentou uma curva contínua e decrescente (J invertido) em cada ano de observação, confirmando seu enquadramento no grupo ecológico das espécies tolerantes à sombra.

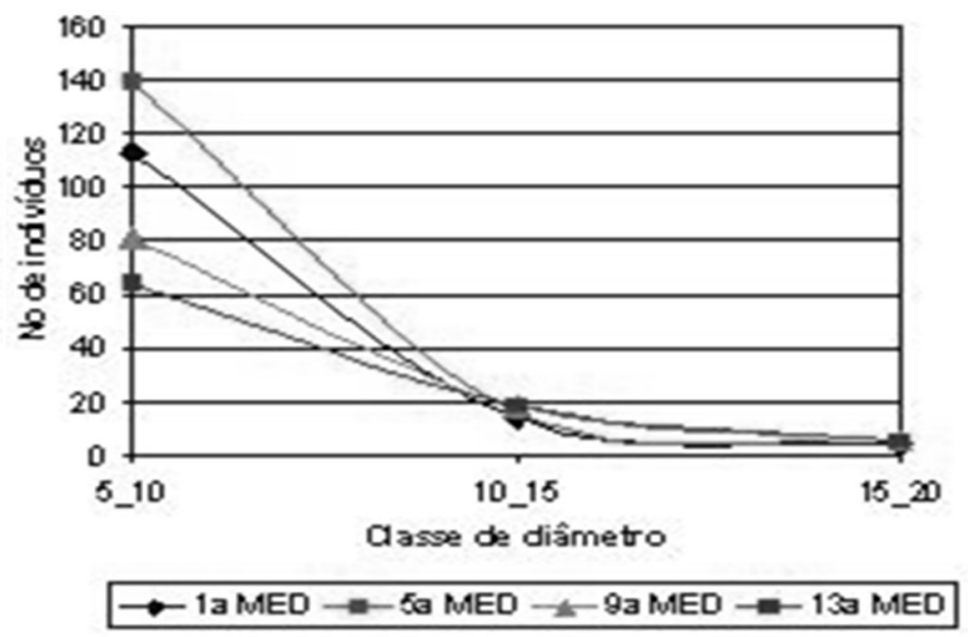

Figura 14: Distribuição diamétrica da população de Protium pallidum Cuatrec. Com DAP $\geq 5 \mathrm{~cm}$ em três anos de monitoramento, em uma floresta tropical primária explorada seletivamente no Município de Moju, Estado do Pará, Brasil.

Durante todo o período de observação, a distribuição diamétrica da espécie se apresentou na forma exponencial decrescente ou "J invertido" na área estudada, seguindo um padrão que mesmo não sendo comum em populações, é normalmente encontrado em povoamentos naturais (HARTSHORN, 1978).

Bartoszecki et al. (2004), em seus estudos sobre a distribuição diamétrica para bracatingais em Curitiba-PR, também encontraram resultados semelhantes, com maior concentração das árvores na classe diamétrica de 7 a $8 \mathrm{~cm}(14,2 \%)$ e que até a classe de $8 \mathrm{~cm}$ perfazem um total de $57,5 \%$ e a partir desta um percentual de $42,5 \%$.

Baggio et al. (1997), em trabalho realizado também com bracatingais da região metropolitana de Curitiba, relataram que em média 36,5 \% das árvores não ultrapassam $7 \mathrm{~cm}$ de diâmetro e maior frequência de árvores se encontra na classe de 7,1 a 9cm de diâmetro, alegando que a tendência em bracatingais é de uma concentração de árvores nas classes diamétricas inferiores, mas que a mesma pode ser influenciada pelo manejo realizado em cada bracatingal, além de outros fatores como os ambientais.

Essa distribuição garante que, no processo dinâmico da floresta, a espécie se perpetue, pois, a morte de indivíduos grandes, geralmente por senescência, dá lugar ao desenvolvimento de indivíduos jovens 
(LONGHI, 1980). De um modo geral, Protium pallidum Cuatrec. apresentou as características de uma espécie tolerante à sombra, pois se desenvolve muito bem nos ambientes mais sombreados, ou seja, no eixo onde a radiação é menor e nas áreas mais distantes do centro das clareiras.

Ressalta-se também neste capítulo que os resultados referentes as taxas de ingresso e mortalidade e ao ICA, explicam cerca de 10 a $12 \%$ das variações ocorridas para o nível de indivíduos com DAP $\geq 5 \mathrm{~cm}$, sendo também conveniente a avaliação de novos parâmetros, mais medições e/ou até mesmo a aplicação de outros métodos para a avaliação dessa dinâmica populacional.

\section{CONCLUSÕES}

A população de Protium pallidum Cuatrec. com DAP $\geq 5 \mathrm{~cm}$ não sofreu influência das quatro direções, nem tampouco das distâncias do centro das clareiras em termos de ingresso e mortalidade.

Os altos índices de ingresso aliados a pouca mortalidade indicam que a espécie é favorecida em termos de adaptação e crescimento na área de estudo, contudo, ressalta-se que as análises apresentam resultados de apenas três anos, recomendando-se um maior período de monitoramento para conclusões mais detalhadas.

As interações entre as direções e as distâncias em relação ao crescimento diamétrico de Protium pallidum Cuatrec. no eixo norte-sul, nos locais mais afastados do centro das clareiras, onde a abundância é maior, sugerem a existência de um possível agrupamento de indivíduos nesses locais, por motivos desconhecidos, podendo ser ou não por uma questão de microclima, solo ou outro fator desconhecido, que favoreceu de algum modo o crescimento desses indivíduos.

A distribuição diamétrica da espécie, com maior quantidade de indivíduos nas menores classes de diâmetro, sugere a garantia de sustentabilidade para a mesma, já que demonstra uma boa regeneração natural.

\section{REFERÊNCIAS}

ALDER, D.; SYNNOT, T. J.. Permanent sample plot techniques for mixed tropical forest. Oxford Forestry Institute. University of Oxford. Tropical Forestry Papers, v.25, p.124, 1992.

ARMELIN, R. S.; MANTOVANI, W.. Definições de clareira natural e suas implicações no estudo da dinâmica sucessional em florestas. Rodriguésia, Rio de Janeiro, v.52, n.81, p.5-15, 2001.

BAGGIO, A. J.; CAPARNEZZI, A. A.. Biomassa aérea da bracatinga (Mimosa scabrella Benth.) em talhões do sistema de cultivo tradicional. Boletim de Pesquisa Florestal, Curitiba, v.34, p.31-44, 1997.

BARTOSZECK, A. C. P. S.; MACHADO, S. A.; FIGUEIREDO FILHO, A.; OLIVEIRA, E. B.. A distribuição diamétrica para bracatingais em diferentes idades, sítios e densidades na região metropolitana de Curitiba. Floresta, Curitiba, v.34, n.3, p.305-323, 2004.

CARVALHO, J. O. P.. Dinâmica de florestas naturais e sua
Implicação para o manejo florestal. In: Curso de Manejo Florestal Sustentável. Colombo: EMBRAPA, 1997. p.250.

CRAWLEY, M. J.. Plant Ecology. Oxford: Blackwell Scientific Publications, 1997.

FINEGAN, B.. El potencial de manejo de los Bosques húmedos secundários neotropicales de las tieras bajas. Turrialba, n.5, 1992.

GOMIDE, G. L. A.. Dinâmica sucessional de florestas neotropicais secundárias: Estudos de caso na Amazônia Brasileira e na Costa Rica. Tese (Doutorado em Engenharia Florestal) - Universidade Federal do Paraná, Curitiba, 2003.

HARTSHORN, G. S.. Tree falls and tropical forest dynamics. In: TOMLINSON, P. B.; ZIMMERMANN, M. H.. Tropical tree as living systems. Cambridge: Cambridge University Press, 1978. p.617-638.

HOSOKAWA, R. T.; MOURA, J. B.; CUNHA, U. S.. Introdução ao Manejo e economia de florestas. Curitiba: UFPR, 1998. 
LIEBERMAN, D.; LIEBERMAN, M.. Forest tree growth and dynamics at La Selva, Costa Rica (1969-1982). Journal of Tropical Ecology, v.3, p.347-358, 1987.

LONGHI, S. J.. A estrutura de uma floresta natural de Araucaria angustifólia (Bert.) 0 . Ktze., Sul do Brasil. Dissertação (Mestrado) - Universidade Federal do Paraná, Curitiba, 1980.

LOPES, J. C. A.; WHITMORE, T. C.; BROWN, N. D.; JENNINGS, S. B.. Banco de sementes de uma floresta tropical úmida no município de Moju, PA. In: SILVA, J. N. M.; CARVALHO, J. O. P.; YARED, J. A. G.. A Silvicultura na Amazônia Oriental: contribuições do projeto silvicultura tropical (Embrapa/DFID). 2 ed. Belém: Embrapa Amazônia Oriental, 2001. p.367-392.

MALHEIROS, M. A. B.. Caracterização do fluxo de radiação fotossinteticamente ativa, irradiância espectral e relação vermelho:vermelho extremo em clareiras da exploração florestal seletiva, em Moju-Pará, Brasil. Dissertação (Mestrado) - Faculdade de Ciências da Administração de Pernambuco, Belém, 2001.

MANOKARAN, N.; KOCHUMMEN, K. M.. Recruitment, grow and mortality of trees in na lowland dipyterocarp forest in Peninsular Malaysia. Journal of Tropical Ecology, n.3, p.315330, 1987.

MELO, M. S.. Florística, fitossociologia e dinâmica de duas florestas secundárias antigas com história de uso diferentes no nordeste do Pará-Brasil. Dissertação (Mestrado) - Escola Superior de Agricultura Luiz de Queiroz, Piracicaba, 2002.

MENDONÇA, A. C. A.. Caracterização e simulação dos processos dinâmicos de uma área de floresta tropical de terra firme utilizando matrizes de transição. Dissertação (Mestrado em Ciências Florestais) - Universidade Federal do Paraná, Curitiba, 2003.

MORY, A. M.. Comportamento de espécies arbóreas em diferentes níveis de desbaste por anelamento. Dissertação (Mestrado em Ciências Florestais) - Faculdade de Ciências da Administração de Pernambuco, Belém, 2000.

MORY, A. M.; JARDIM, F. C. S.. Comportamento de Eschweilera odora (Popp.) Miers (Matamata-branco) em diferentes níveis de desbaste por anelamento. Revista de Ciências Agrárias, Belém, n.36, p.29-53, 2001.

NAPPO, M. E.; GRIFFITH, J. J.; MARTINS S. V.; MARCO JÚNIOR P.; SOUZA, A. L.; OLIVEIRA FILHO, A. T.. Dinâmica da estrutura diamétrica da regeneração natural de espécies arbóreas e arbustivas no sub-bosque de povoamento puro de mimosa scabrella bentham, em área minerada, em Poços de Caldas, MG. Revista Árvore, Viçosa, v.29, n.1, p.35-46, 2005.

NEMER, T. C.. Dinâmica da população de Eschweilera odora (Popp.) Miers (Matamata-branco) em floresta tropical de terra firme manejada, Moju - Pará - Brasil. Dissertação (Mestrado em Ciências Florestais) - Universidade Federal Rural da Amazônia, Belém, 2003.

POPMA, J.; BONGERS, F.; MARTÍNEZ-RAMOS, M.; VENEKLAAS, E.. Pioneer species distribution in treefall gaps in neotropical rain forest; a gap definition and its consequences. Journal of Tropical Ecology, v.4, p.77-88, 1988.

PUTZ, F. E.; BROKAW, N. V. L.. Sprouting of broken trees on Barro Colorado Island, Panama. Ecology, v.70, n.2, p.508512, 1989.

SCHORN, L. A.. Estrutura e dinâmica de estágios sucessionais de uma floresta ombrófila densa em Blumenau, Santa Catarina. Tese (Doutorado em Ciências Florestais) - Universidade Federal do Paraná, Curitiba, 2005.

SILVA, S. M. A.; SILVA, J. N. M.; BAIMA, A. M. V.; LOBATO, N. M.; THOMPSON, I. S.; COSTA FILHO, P. P.. Impacto da exploração madeireira em floresta de terra firme no município de Moju, Estado do Pará. In: SILVA, J. N. M.; CARVALHO, J. O. P.; YARED, J. A. G.. A silvicultura na Amazônia Oriental: Contribuições do projeto Embrapa-DFID. Belém: Embrapa Amazônia Oriental, 2001. p.309-323.

SILVA, J. N. M.. The behaviour of the tropical rain forest of the Brazilian Amazon after logging. Thesis (PhD) - University of Oxford, Oxford, 1989.

SWAINE, M. D.; LIEBERMAN, D.; PUTZ, F. E.. The dynamics of tree populations in tropical forest: a review. Journal of Tropical Ecology, n.3, p.359-366. 1987.

VANCLAY, J. K.. Modelling forest growth and yield: applications to mixed tropical forests. Wallingford: $C A B$ International, 1994.

VASCONCELOS, L. M. R.. Avaliação da dinâmica populacional de Rinorea guianensis Aublet (Acariquarana) Violaceae, em uma floresta tropical primária explorada seletivamente, Moju - PA. Dissertação (Mestrado em Ciências Florestais) - Universidade Federal Rural da Amazônia, Belém, 2004

A CBPC - Companhia Brasileira de Produção Científica (CNPJ: 11.221.422/0001-03) detém os direitos materiais desta publicação. Os direitos referem-se à publicação do trabalho em qualquer parte do mundo, incluindo os direitos às renovações, expansões e disseminaç̃̃es da contribuição, bem como outros direitos subsidiários. Todos os trabalhos publicados eletronicamente poderão posteriormente ser publicados em coletâneas impressas sob coordenação da Sustenere Publishing, da Companhia Brasileira de Produção Científica e seus parceiros autorizados. Os (as) autores (as) preservam os direitos autorais, mas não têm permissão para a publicação da contribuição em outro meio, impresso ou digital, em português ou em tradução. 